\title{
Exploring the impact of organizational investment on occupational fraud: mediating effects of ethical culture and monitoring control
}

Joon Bae Suh

PhD Student, University of Portsmouth, United Kingdom.

Hee Sub Shim

Assistant Professor at Department of Public Administration \& Police Science, Hannam University, South Korea

Mark Button

Director of the Centre for Counter Fraud Studies, University of Portsmouth, United Kingdom.

Published online on 14 March 2018 in International Journal of Law, Crime and Justice

\begin{abstract}
:
There has been no clear evidence about whether organizational investment works for countering occupational fraud, and where to focus the investment if it works. In this regard, the present study explored the mediating roles of ethical culture and monitoring control in the 'organizational investment-occupational fraud' linkage. Using a sample of 392 Korean banking employees, a series of structural equation models were estimated. The results showed that the perception of increased investment in anti-occupational fraud enhanced two mediating variables, ethical culture and monitoring control. However, only the perception of an improved ethical culture was negatively related to the perceived frequency of occupational fraud with statistical significance. These findings imply that investing in ethical culture is more effective in preventing occupational fraud.
\end{abstract}

Keywords: Occupational fraud, Anti-occupational fraud investment, Ethical corporate culture, Monitoring control, Fraud triangle

\section{Introduction}

The financial system of a country is the lifeblood of the economy. Commercial banking is a significant part of the financial system, providing core financial services such as savings accounts, investments, loans, mortgages and other services to ordinary people (Saunders and Cornett, 2008). The employees who serve these banking institutions are exposed to a range of opportunities to commit financial crimes and related acts (Hollow, 2014; Mitchell et al., 1992). White-collar crimes in the banking sector breach public trust in the financial system and can have a very detrimental effect on the whole economy. For example, the Savings and Loan (hereafter, S\&L) scandal in the 1980s in the US had a significant impact on the economy. This debacle is regarded as the worst archetype of white-collar crime because fraud and illegal activities involving executives and managers of S\&L 
institutions were so prevalent that they led to financial catastrophe (Friedrich, 2010). The directors and managers of $S \& L$ institutions threw extravagant parties and purchased luxury villas or yachts from embezzled money, which represented acute moral hazard. The debacle led some to conclude that "the best way to rob a bank is to own one" and the term 'collective embezzlement' was coined to explain the failure of the financial institutions (Black, 2013; Calavita and Pontell, 1991).

South Korea (hereafter, Korea) is also not immune from white-collar crime within its banking institutions. In 2011, more than 20 savings banks went bankrupt or were suspended by the financial authority due to occupational fraud and illegal activities (Min, 2012). The number of victims reached 100,000 people with losses estimated at around \$26 billion. The crisis ended with many workingclass families losing their life-long savings and in some cases tragic loss of life, by some committing suicide (The Kyunghyang Shinmun, 2012). The collapse of the financial institutions was attributed to internal fraud and corruption. For instance, the elder brother of the then Korean President and a leading congressman were arrested for receiving bribes from the director of a savings bank (KBS News, 2012). Aside from the savings bank scandal, official statistics recorded 147 embezzlement cases by bank employees in Korea, amounting to $f 30.6$ million between 2011 and 2015. The average loss to embezzlement by bank employees was estimated at $£ 210,000$ per case (Kim, 2015).

Despite the very serious and significant impacts on society, empirical studies on occupational fraud in the financial sector have been very limited. To bridge the paucity of information, this study surveyed 392 Korean banking sector employees with respect to their perception and experience of occupational fraud in their organization. Although previous studies attempted to discover what control mechanisms (e.g., background checks, hotline, risk assessment, audit, etc.) are effective in preventing and detecting fraud (Holtfreter, 2005a, 2005b, 2008; Johansson and Carey, 2015; Kummer et al., 2015; Tunley et al., 2017), few studies have tried to investigate the impact of 'organizational investment' on occupational fraud. Furthermore, Murphy and Free (2016) called for more research on the relationship between 'ethical culture/climate' and 'fraud.' They argued that the current framework, the Fraud Triangle, has a limited scope of analysis by just diagnosing fraud as the problem committed by immoral individuals who should be 'monitored' through control mechanisms; this has led to assess fraud risk in a narrow approach focusing only on monitoring aspects. Therefore, the current study not only attempts to fill the gap of research on 'organizational investment,' but also to contribute to anti-fraud community by simultaneously exploring the effects of 'ethical culture' and 'monitoring effectiveness' on occupational fraud, in which lies the novelty and significance of the study. Following an explanation of the background, method and findings of the study, its implications and limitations are considered.

\section{Literature review}

\section{1. Occupational fraud and the Fraud Triangle}

Occupational fraud is sometimes called 'internal,' 'insider,' or 'employee' fraud (Bonny et al., 2015; Edge, 2016; Gunduz and Onder, 2013; Rossi, 2012) or just referred to as fraud (Holtfreter, 2005a, 2005b, 2008; Murphy and Free, 2016). The Association of Certified Fraud Examiners (ACFE), the world's biggest anti-fraud organization defines 'occupational fraud' as "the use of one's occupation for personal enrichment through the deliberate misuse or misapplication of the employing organization's resources or assets" (ACFE, 2012: 6-7). Therefore, 'occupational fraud' is fraud against 
an organization committed by members of an organization, which range from ordinary employees through to managers to executives. It entails three categories: (1) asset misappropriation, which includes the theft or misuse of an organization's asset; (2) corruption, where employees use their influence in business transaction to obtain unauthorized benefits contrary to their duties to employers; (3) fraudulent financial statements, which normally involve making reported financial statements look better than they really are (ACFE, 2012; Albrecht et al., 2015; Holtfreter, 2005b; Wells, 1997).

Holtfreter (2005b) found that the individuals who committed 'fraudulent statements' were more likely to be older, educated males with managerial positions conforming to the high status image of 'white-collar crime' (Sutherland, 1961), whereas those perpetrated 'asset misappropriation' or 'corruption' more closely resembled 'middle-class' offenders (Weisburd et al., 1991); in terms of organizational characteristics, 'asset misappropriation' was committed significantly more often in smaller organizations, whereas 'corruption' occurred in larger organizations more frequently. The definition and typology of 'occupational fraud' developed by the ACFE has provided an especially powerful way of analyzing white-collar crime at a workplace level and many previous studies adopted the ACFE's definition and typology for their analysis of fraud (Greenlee et al., 2007; Holtfreter, 2005a, 2005b, 2008; Johansson and Carey, 2015; Timofeyev, 2015). When fraud is commonly referred in this paper, the authors also adopt the concept of 'occupational fraud' by the ACFE.

According to the ACFE's biennial reports, almost every organization is a victim of occupational fraud and the typical organization loses approximately 5 percent of its annual revenue with the median loss of one case estimated at around $\$ 150,000$ (ACFE, 2012, 2014, 2016). Therefore, studying what works for countering it is very important. Cressey's Fraud Triangle Theory depicts that there is a high probability of fraud when pressure (incentive), opportunity, and rationalization (attitude) intermingle at the same time (Cressey, 1953; Wells, 1997). However, some imply that all three elements only apply to 'first time' or 'accidental' offenders and not to repeat offenders, who are known as 'predators.' In the case of the latter, only one condition is necessary to commit fraud, which is opportunity (Dorminey et al., 2010, 2012). Although challenges and caveats have been made to the Fraud Triangle (Lokanan, 2015; Schuchter and Levi, 2016), the theory is established as a useful framework not only for assessing the risk of fraud but also for presenting ways of countering fraud (AICPA, 2002). For example, 'opportunity' can be reduced by strengthening control mechanisms to increase the probability of detection and punishment in organizations (ACFE, 2015; Albrecht et al., 2015; Dorminey et al., 2010, 2012).

Furthermore, having an ethical culture/climate is suggested as a solution to eliminate the other elements of the Triangle, 'rationalization' and 'pressure' (Murphy and Free, 2016; Dorminey et al., 2010; Rodgers et al., 2015). The individual level 'rationalization' and 'pressure' have been hard to observe because both are happening in a subjective human mind. Moreover, only occupational offenders actually experience the concurrence of the three elements by actually committing fraud, whilst normal employees do not often encounter them simultaneously. This hence made empirical studies of all three elements very complicated (Schuchter and Levi, 2016). However, if the unit of analysis is converted to the organizational level, 'ethical corporate culture' can be a proxy measure which is negatively associated with the strength of 'rationalization' and 'pressure' in a company (Dorminey et al., 2010; Murphy and Free, 2016). Despite the suggested link between the ethical culture and the two elements, empirical analysis for this expanded solution cannot be found in the 
extant literature. In this regard, the present study endeavours to enlarge Fraud Triangle Theory by measuring 'monitoring effectiveness' and 'ethical culture' in organizations rather than directly assessing individual offender's perceived 'pressure,' 'opportunity,' and 'rationalization.'

\section{2. Deterrence and monitoring control}

Traditionally, deterrence was stressed as a way of combatting crime. The more certain, severe, and swifter the punishment can be perceived by individuals, the more deterrence of crimes can be achieved as a corollary of perceptual deterrence (Erickson et al., 1977; Paternoster, 1989). Especially, between the certainty and severity of punishment, many agree that perceived certainty is more effective in deterring crime (Apel and Nagin, 2011; Hollinger and Clark, 1983). Interestingly, a deterrence/rational choice theory would be more suitable in understanding occupational fraud because corporations are normally composed of rational individuals who want to maximize profits (Simpson et al., 2013). This approach, therefore, mainly utilized methods to swell the perceived certainty of detection by focusing on monitoring and surveillance in organizations. In order to monitor and discover insider fraud, traditional methods such as internal/external auditing have been utilized in many companies although those measures sometimes necessitated time-consuming investigations and adequate organizational investments (Button and Gee, 2013).

However, with the rapid growth of IT technology, computerized fraud monitoring systems have emerged using advanced information techniques to detect fraud and track fraudsters in a real time basis (Giles, 2012). For example, a constant monitoring programme (also called as fraud pattern analysis) was implemented to identify anomalies, triggering points, and risk indicators using large data sets in many financial institutions. This programme searches for red flags that require further investigation and enables management or auditors to identify fraudulent activity much quicker, thereby reducing the cost of fraud (ACFE, 2012, 2014, 2016). Plus, auditing software and programmes have significantly advanced to find evidence of fraud more precisely using state of the art technology (Singleton and Singleton, 2010). The Korean banking industry has also adopted this technological innovation to strengthen its capacity of detection of occupational fraud (Datanet, 2015).

\section{3. Ethical culture}

The coso internal control system that most organizations are currently implementing was established in response to the S\&L Debacle, in reflection of the limited capability of traditional control mechanisms and to further integrate 'ethical culture' into the control system (Alleyne and Amaria, 2015; Singleton and Singleton, 2010). Trevino defines ethical culture as "a subset of organizational culture, representing a multidimensional interplay among various formal and informal systems of behavioral control that are capable of promoting ethical behavior" (Trevino et al., 1998: 451). Schwartz (2013) argued that three essential elements must be present if illegal or unethical activities are to be minimized through maintaining an ethical corporate culture. The three elements entail (1) the existence of core ethical values embedded throughout the corporation in its policies, process, and practices; (2) the establishment of a formal ethics programme such as ethics training; (3) the continuous presence of ethical leadership, which is an appropriate 'tone at the top' as reflected by the board of directors and senior managers. By the same token, Button and Brooks (2009) maintained that there are three main factors that affect anti-fraud culture in organizations: (1) a 
clear statement of ethical behaviour; (2) staff vetting such as background checks to create an honest work-environment; (3) maintaining a positive working morale by such as good salary, all of which require adequate investments in the organizations.

\section{4. Anti-occupational fraud investment}

Findings from a Global Survey of Economic Crime showed that the number of controls and detection measures in organizations was one of the most significant explanatory variables for the detection of crimes in an organization (Bussman and Werle, 2006). For example, companies that reported no victimization had significantly fewer controls while companies assigning more employees to control related tasks were more likely to detect possible fraud (Choi et al., 2013). Lee (2013) also found that the percentage of personnel responsible for monitoring financial statement fraud is positively associated with a good earnings 'quality': where company earnings are comprised of real cash flows rather than account receivables. Other studies have also implicated a high probability of occupational fraud when employees feel underpaid by a company or insecure about their job stability (Greenberg, 1990; Lawrence and Kacmar, 2017).

However, the hidden and secretive nature of occupational fraud makes it difficult for executives or directors of companies to realize the necessity of investments in countering occupational fraud. If one inventory item was misappropriated by an employee and the profit margin is 20 percent in the company, the losses can be recovered only after selling 5 additional items at a regular price (ACFE, 2015). In a fiercely contested market situation, a competitive advantage can therefore be achieved by investing in anti-occupational fraud to reduce this hidden cost associated with fraud (Button and Gee, 2013).

Nonetheless, the impact of organizational investment for countering occupational fraud has not been well explained in the previous literature. In this regard, we attempted to discover the impact of organizational investment in financial institutions, where occupational fraud reported most frequently out of all industries (ACFE, 2012, 2014, 2016). Some studies suggested that organizational investment might depend on several factors such as the strategy, size, and leadership of organizations (Bentley et al., 2013; Wheeler and Rothman, 1982; Tunley et al., 2017) implying a multidimensional interplay among various factors in corporate culture. However, given the exploratory nature of the study, we have assumed anti-occupational fraud investment as an exogenous variable and attempt to see its influences on mediating and endogenous variables sequentially.

From the literature review so far, we have developed the following hypotheses for the present study.

Hypothesis 1: There is a negative relationship between the perceived investment in antioccupational fraud and the perceived frequency of occupational fraud.

Hypothesis 2A: If the employees agree more that proper budget and human resources are invested in anti-occupational fraud, then they feel that ethical culture is stronger in their organization. 
Hypothesis 2B: If the employees agree more that proper budget and human resources are invested in anti-occupational fraud, then they feel that the effectiveness of monitoring control is higher in their organization.

Hypothesis 3A: There is a negative relationship between the perceived ethical corporate culture and the perceived frequency of occupational fraud.

Hypothesis 3B: There is a negative relationship between the perceived effectiveness of monitoring control and the perceived frequency of occupational fraud.

In figure 2, our analysis model is presented based on these hypotheses. The relationships between variables are depicted by a solid line (positive effect) or a dotted line (negative effect). In order to maximize the visibility of the model, control variables are not described.

Figure 2: Respective path hypotheses.

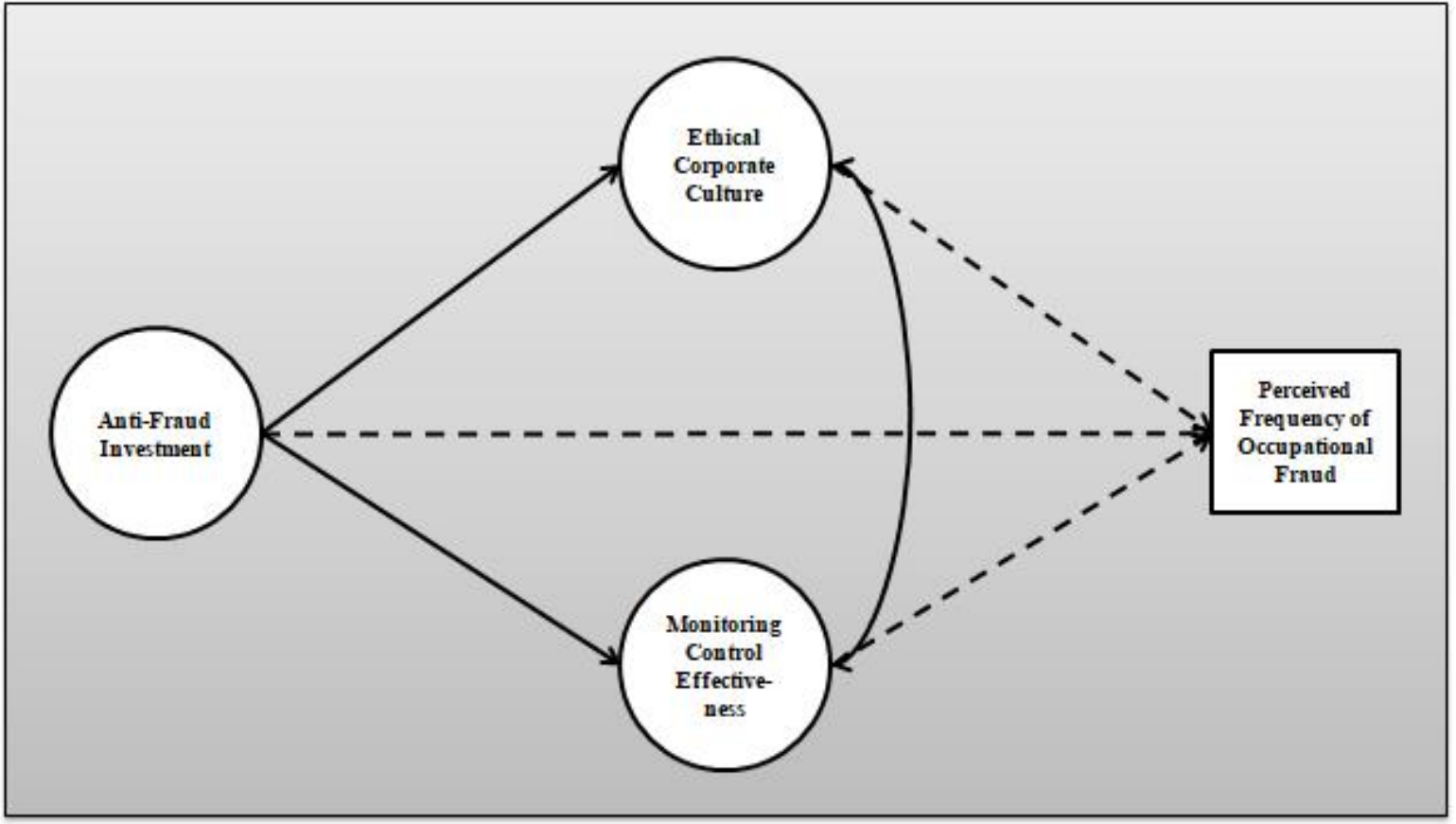

Notes: latent variable $=$ circle, observed variable $=$ square; solid line $(-)=$ positive effect, dashed line $(---)=$ negative effect 


\section{Research method}

\section{1. Sampling and data}

For data collection, a quota sampling method was administered to the employees in the Korean banking industry from June to September 2016. The survey questionnaire utilized a web-based platform easily accessed via social network and email services through mobile phone or any computers. An informed consent form was posted on the opening webpage notifying their participation was voluntary and confidential. A total of 444 responses were collected but only 392 were usable for the analysis because of missing values in some returns. The full information maximum likelihood (FIML) method was utilized for the missing values, which is evaluated as the best technique to minimize a bias regardless of their distribution (Enders, 2006; Schafer and Graham, 2002). Six different types of banking institutions were included in the sample: (1) nationwide bank (45\%), (2) regional bank (7\%), (3) local agricultural \& fishery cooperative bank (21\%), (4) community credit bank (8\%), (5) credit union bank (15\%), and (6) savings bank (5\%); these percentages represent a similar proportion of the bank employee population in Korea. In addition, the organizational characteristics of the respondents include the followings: (1) 68 percent had less than 5,000 employees; (2) 82 percent had an anti-occupational fraud department in the bank; (3) 48 percent respondents were working for the second financial sector (community banks) whilst the others were working for the first financial sector (commercial banks).

Table 3: Sample size by the type of depository financial institutions in Korea

\begin{tabular}{|c|c|c|c|}
\hline Financial sector & Type & Subtype & Sample size \\
\hline \multirow{2}{*}{ The first sector } & \multirow{2}{*}{ Commercial banks } & Nationwide bank & $177(44.8 \%)$ \\
\hline & & Regional bank & $28(7.1 \%)$ \\
\hline \multirow{4}{*}{$\begin{array}{l}\text { The second } \\
\text { sector }\end{array}$} & \multirow{3}{*}{ Credit unions } & $\begin{array}{c}\text { Local agricultural \& fishery } \\
\text { cooperatives bank }\end{array}$ & $81(20.5 \%)$ \\
\hline & & Community credit bank & $32(8.1 \%)$ \\
\hline & & Credit union bank & $58(14.7 \%)$ \\
\hline & Savings institutions & Savings bank & $19(4.8 \%)$ \\
\hline
\end{tabular}




\section{2. Measurement of variables}

\subsubsection{Endogenous variable}

To capture the endogenous variable, 'the perceived frequency of occupational fraud,' we developed a single item by directly asking respondents how many occupational frauds had occurred in their bank within the last five years. The response ranged from 0 to 10 and the mean was 3.45 with a standard deviation of 2.589. Following West et al. (1996), the normal distribution assumption was satisfied. The frequency responses were directly utilized for the analysis without any change.

\subsubsection{Exogenous variable}

The exogenous variable, 'anti-occupational fraud investment' was measured with two items using 5 point-Likert scale ( $1=$ strongly disagree, $5=$ strongly agree). One item focused on responses to the levels of budgetary investment through the statement: "I perceive that the amount of funding dedicated in my organization to fight against occupational fraud is appropriate." This produced a mean of 3.06, and a standard deviation of 0.994 . The second item collected responses on human resource investment through the statement: "I perceive that the amount of human resources dedicated in my organization to fight against occupational fraud is appropriate." This produced a mean of 3.03 and a standard deviation of 1.01. All items satisfied the normal distribution and were loaded as one factor.

\subsubsection{Mediating variables}

One of the mediating variables, 'ethical corporate culture' was measured by 3 items with 5 point Likert scale ( 1 = strongly disagree, 5 = strongly agree) adapted from the Schwartz's study (2013). The reliability of the scale was high with a Cronbach's $\alpha$ of 0.870 . One item was about the presence of ethical leadership using the following statement: "Proper tone at the top such as management's honesty and integrity is well established." This produced a mean of 3.28 and a standard deviation of 1.13. The respondents were then asked about their ethical culture: "A strong ethical corporate culture exists in the bank," which produced a mean of 3.58 and a standard deviation of 1.12. Finally, the respondents were asked about the core ethical values such as workplace integrity: "The integrity of my workplace is high." produced a mean of 3.87 and a standard deviation of 1.00. All three items were normally distributed and were loaded as one factor.

The other mediating variable, 'effectiveness of monitoring control' was specified by 4 items with 5point Likert scale ( 1 = strongly disagree, 5 = strongly agree) adapted from the study of Dorminey et al $(2010,2012)$. The reliability of the scale was very high with a Cronbach's $\alpha$ of 0.938 . The four items are (1) "Internal control system is well designed (mean $=3.71$, standard deviation $=0.95) . "$; (2) "Internal control system is in good operation as designed (mean $=3.66$, standard deviation $=0.96)$."; (3) "Continuous monitoring system is in good operation (mean $=3.79$, standard deviation $=0.99$ )."; (4) "Auditing tools and programmes in our bank are effective (mean $=3.70$, standard deviation = 1.01)." All items were normally distributed and confirmed as one factor.

\subsubsection{Control variables}

For our study, the unit of analysis was set at the organizational level. Therefore, only the organizational characteristics of the respondents were included. Three organizational characteristics and five different bank types were coded as a dummy variable. The three organizational variables 
included: (1) the size of organization ${ }^{1}(1=$ small \& medium sized, $0=$ large; mean $=0.68),(2)$ the existence of anti-occupational fraud department in the bank ( $1=$ yes, $0=$ no; mean $=0.82)$, and ( 3 ) working for the second financial sector $(1=$ yes, $0=$ no; mean $=0.48)$. The size of organization was selected as a control variable because previous studies indicated that crime is related to the size and influence of organizations (Coleman, 1987; Wheeler and Rothman, 1982). The existence of antioccupational fraud department was chosen because the authors believed that it is related to antifraud strategy of organizations (Bentley et al. 2013). Lastly, the unique characteristics of the financial sector were controlled to prevent any confounding effects on the endogenous variable. In the model, the savings bank was designated as reference group and 5 types of different banks were all dummy coded: (1) nationwide bank ( $=1$, non-nationwide bank $=0$; mean $=0.45),(2)$ regional bank $(=1$, nonregional bank $=0$; mean $=0.07),(3)$ local agricultural $\&$ fishery cooperatives bank $(=1$, non-local agricultural \& fishery cooperatives bank $=0$; mean $=0.20),(4)$ community credit bank $(=1$, noncommunity credit bank $=0$; mean $=0.08)$, $(5)$ credit union bank $(=1$, non-credit union bank= 0 ; mean $=0.15)$.

\section{Findings}

\section{1. Analysis strategy}

The general two-stage approach of structural equation modeling (SEM) was adopted. Firstly, a preliminary test was conducted through a measurement model to check the acceptability of whether to proceed to the next stage. For that, we examined all the values of standardized factor coefficient, R-Square, and bivariate correlation. Secondly, a structural model estimated not only the direct pathway linking 'anti-occupational fraud investment' to 'the perceived frequency,' but also the mediating effects of two respective variables ('ethical corporate culture' and 'effectiveness of monitoring control'). Bias-corrected (BC) bootstrapping methods were utilized to minimize the concern about the normal distribution assumption and the probability of type I error. In addition, the fixed coefficient models were estimated to reduce the concern regarding the independence assumption by six different bank types being dummy coded. The Mplus 7.0 programme was utilized for our analysis.

\section{2. Measurement model}

A total of three latent constructs were included in the measurement model, showing the acceptable model fit indices: root-mean-square error of approximation (RMSEA) $=0.051$, comparative fit index $(\mathrm{CFI})=0.991$, Tucker-Lewis index $(\mathrm{TLI})=0.987$, and standardized root-mean-square residual (SRMR) $=0.015$. Moreover, the values of standardized factor coefficients ranged from 0.805 to 0.916 and all were statistically significant $(p<0.001)$. The respective values of R-Square ranged from 0.648 to 0.875 indicating an acceptable explanatory power.

Table 4 demonstrates the values of bivariate correlations among the latent variables. Given that all correlation values were below 0.80, no collinearity issue was found (Byrne, 2012). As predicted by our theoretical model, the relationships were all positively correlated among the latent variables.

\footnotetext{
${ }^{1}$ If the total number of employees is less than 5,000 (mean in the sample) in the banking institution, it was categorized as a small \& medium sized organization.
} 
Table 4: Bivariate correlation matrix for the latent variables $(n=392)$.

\begin{tabular}{cccc}
\hline & AFI & ECC & MCE \\
\hline $\begin{array}{c}\text { Anti-occupational } \\
\text { Fraud Investment (AFI) }\end{array}$ & 1.000 & & \\
Ethical Corporate & & & \\
Culture (ECC) & $0.421^{* * *}$ & 1.000 & \\
Monitoring Control & & & \\
Effectiveness (MCE) & $0.357^{* * *}$ & $0.624^{* * *}$ & \\
\hline
\end{tabular}

Notes: $* * p<0.001$

Although Table 4 does not indicate any issues of collinearity, 'ethical corporate culture' ( 3 items) and 'effectiveness of monitoring control' ( 4 items) appeared to be relatively highly correlated (0.624). To ease the concern, an additional exploratory factor analysis (EFA) was conducted to compare the integrated one-factor solution ( 7 items) with the original two-factor solution. A series of EFA models showed that the original two-factor design ('ethical corporate culture' and 'monitoring control effectiveness') was far superior in the model fit indices.

\section{3. Structural model}

The structural part (shaded in figure 3) was composed of three latent variables and one observed variable. A two parallel mediator model was estimated using 'anti-occupational fraud investment' as the exogenous variable; 'ethical corporate culture' and 'monitoring control effectiveness' as two mediating variables; the 'the perceived frequency' as the endogenous variable. The eight dummy variables outside the shaded box were designed to control for the theoretical variables inside the shaded area. All the parameters were drawn from 2,000 bootstrap samples.

Figure 3: Structural equation modeling analysis $(n=392)$. 


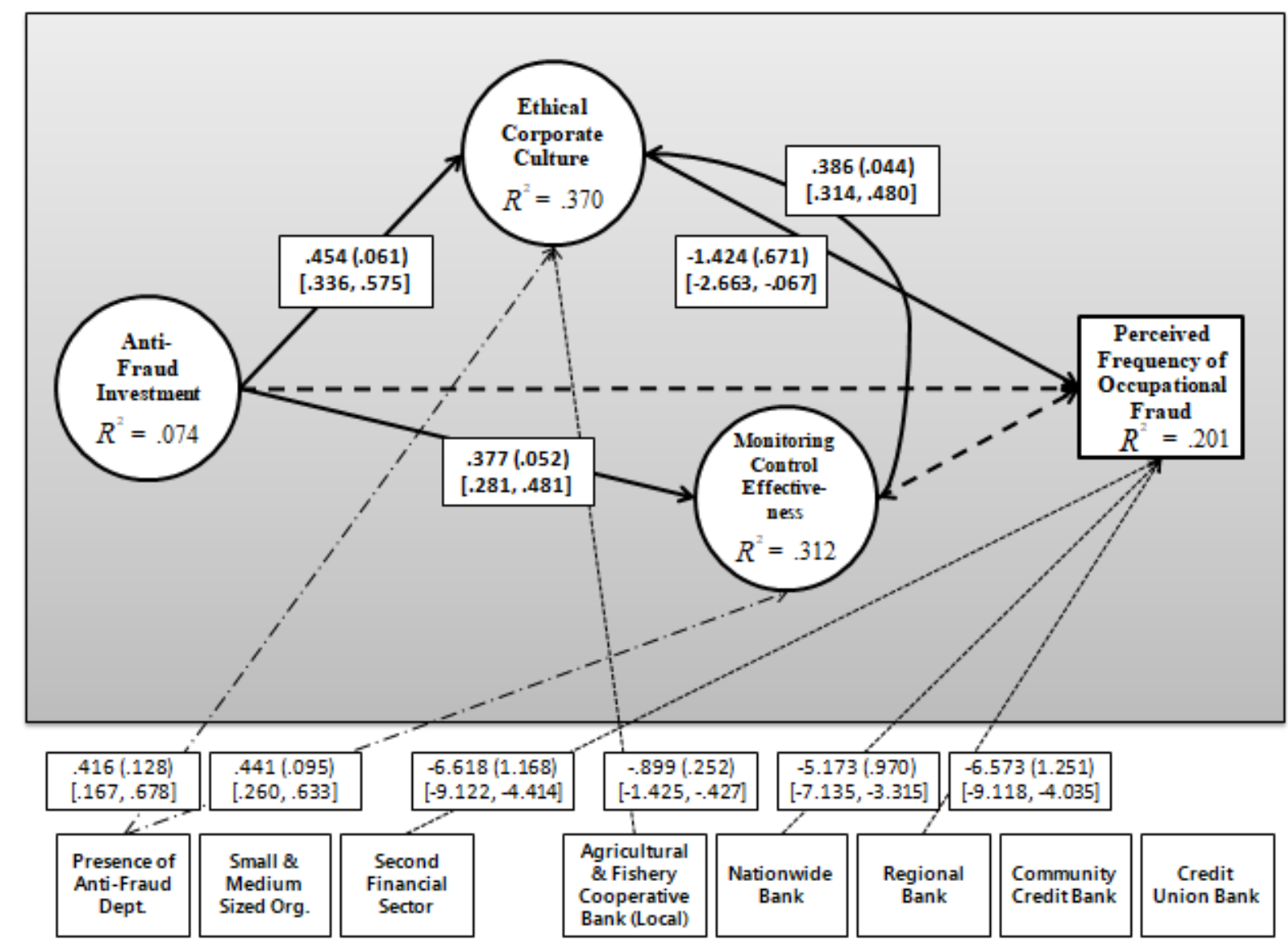

Notes: solid line $(-)=$ significant effect, dashed line $(---)=$ insignificant effect, dashed-dotted line $(-\cdot-\cdot)=$ positive effect,

dotted line $(\cdots)$ = negative effect; Unstandardized path coefficient, standard error (parentheses), BC (bias-corrected) 95\% $\mathrm{Cl}$ (confidence interval) (brackets), and R-square values are reported.

The structural model demonstrated ideal model fit indices and confirmed a high explanatory power $(\mathrm{RMSEA}=0.036, \mathrm{CFI}=0.986, \mathrm{TLI}=0.978, \mathrm{SRMR}=0.022)$. Furthermore, significant variances in the theoretical variables were explained by the analytic model: $7.4 \%$ in 'anti-occupational fraud investment,' $37.0 \%$ in 'ethical corporate culture,' $31.2 \%$ in 'monitoring control effectiveness,' and $20.1 \%$ in 'the perceived frequency.' Among three pathways (one direct and two indirect pathways) in the relationship between the exogenous variable and the endogenous variable, only one indirect pathway was found to be statistically significant. As expected, 'anti-occupational fraud investment' statistically significantly increased both the 'ethical corporate culture' $(\mathrm{BC} 95 \% \mathrm{Cl}[0.336,0.575])$ and 'monitoring control effectiveness' (BC 95\% Cl $[0.281,0.481]$ ) supporting our hypotheses $2 \mathrm{~A}$ and $2 \mathrm{~B}$. However, only the enhanced perception of 'ethical corporate culture' sequentially decreased 'the perceived frequency of occupational fraud' in a statistically significant way $(\mathrm{BC} 95 \% \mathrm{Cl}=[-2.663$, 0.067]) supporting our hypothesis $3 \mathrm{~A}$.

Interestingly, three control variables negatively affected the endogenous variable; those dummy variables were 'the second financial sector' (BC 95\% $\mathrm{Cl}=[-9.121,-4.414])$, 'nationwide bank' (BC 95\% $\mathrm{Cl}=[-7.135,-3.315])$, and 'regional bank' (BC 95\% Cl $=[-9.118,-4.035])$. In other words, the respondents working for the second financial sector appeared to perceive the smaller frequency of occupational fraud than those working for the first financial sector. In a similar vein, the employees 
working for nationwide and regional bank reported the lower perceived frequency compared to those working for savings bank (the reference group).

In sum, the SEM model demonstrated a full mediation relationship with respect to the indirect pathway linking 'anti-occupational fraud investment' to 'the perceived frequency' with 'ethical corporate culture.' An additional test was conducted to confirm the statistical significance of the mediation pathway. As reported in table 5, the linkage of 'anti-occupational fraud investment ethical corporate culture - the perceived frequency of occupational fraud' was found to be statistically significant $(\mathrm{BC} 95 \% \mathrm{Cl}=[-1.316,-0.036])$, whereas no significant relationship was found in other pathways.

Table 5: Significance test of direct and indirect pathways $(n=392)$.

\begin{tabular}{|c|c|c|c|}
\hline Parameter & $B$ & SE & $\mathrm{BC} 95 \% \mathrm{Cl}$ \\
\hline \multicolumn{4}{|l|}{ Direct effect } \\
\hline $\begin{array}{l}\text { Anti-occupational fraud investment } \\
\rightarrow \text { Perceived frequency of occupational } \\
\text { fraud }\end{array}$ & 0.258 & 0.328 & {$[-0.369,0.901]$} \\
\hline \multicolumn{4}{|l|}{ Indirect effect } \\
\hline $\begin{array}{l}\text { Anti-occupational fraud investment } \\
\rightarrow \text { Ethical corporate culture } \\
\rightarrow \text { Perceived frequency of occupational } \\
\text { fraud }\end{array}$ & $-0.647 a$ & 0.324 & {$[-1.316,-0.036]$} \\
\hline $\begin{array}{l}\text { Anti-occupational fraud investment } \\
\rightarrow \text { Monitoring control effectiveness } \\
\rightarrow \text { Perceived frequency of occupational } \\
\text { fraud }\end{array}$ & 0.417 & 0.270 & {$[-0.057,0.977]$} \\
\hline
\end{tabular}

Notes: $a=$ significantly different from zero

\section{Discussion and conclusion}

The S\&L Debacle in the US, the Barings Bank fiasco in the UK, the savings bank collapse in Korea, and the sub-prime mortgage crisis all around the world have demonstrated how significant the consequences of problems in the financial sector can be. However, like other white-collar crimes, the invisible and secretive nature of fraud inside the banking institutions has limited the empirical analysis so far undertaken in this field. Because of this lack of research, there has been no clear evidence about whether organizational investment works for countering occupational fraud, and where to focus the investment if it works. In this regard, the present study explored the impact of anti-occupational fraud investment and discovered the more effective pathway in preventing occupational fraud between two methods expanded from Fraud Triangle Theory.

The result of our analysis showed that the perception of increased investment has statistically significantly enhanced two mediating variables, the 'ethical corporate culture' and 'effectiveness of monitoring control.' However, only the perception of an improved ethical culture was negatively related to the perceived frequency of occupational fraud with statistical significance. This finding 
implies that developing an ethical culture is more effective than monitoring controls for the banking institutions to prevent occupational fraud. In a similar vein, the COSO's integrated internal control also emphasizes the 'tone at the top,' 'integrity,' and 'ethical values' of organizations as its first component of the framework, namely 'control environment' (COSO, 2013). However, it should be noted that the two mediating variables in our sample were positively correlated $(0.624)$, which hints that the two constructs interact for the same end (Weaver and Trevino, 1999). Other studies also found evidence of the importance of control effectiveness (Johansson and Carey, 2016; Rae and Subramaniam, 2008).

With regard to the reason for 'monitoring control' not playing a mediating role in our study, it can be explained by several possible hypotheses. Firstly, because the banking sector has traditionally been severely regulated compared to other industries, this might have brought fatigue among the employees about 'monitoring control.' Also, in terms of cultural context, Korea has been historically influenced by Confucian ideas stressing a hierarchical group culture (Batzeveg et al., 2017; Jang and Hwang, 2014). In such culture, it might be more difficult to prevent management override and collusive fraud which are regarded as the Achilles heel of fraud prevention (AICPA, 2016; Tipgos, 2002). This might have resulted in the employees' imperfect perception of the effectiveness of 'monitoring control.' Secondly, because most occupational fraud is committed by 'first time' offenders who are amenable to appeals to morality, not by 'predators' who are immune to those appeals (Dorminey et al., 2010, 2012; Paternoster and Simpson, 1992), our study indicates that setting ethics as the first line of defence is effective in decreasing normal employees' malpractices in organizations (ERC, 2010; Giles, 2015). We believe that these alternative explanations are an important area for future research.

Interestingly, the control variable such as working in the second financial sector (community banks) has lowered the perceived frequency of occupational fraud. However, a caution should be made that this does not necessarily demonstrate evidence that these banking institutions are safer from occupational fraud than the first financial sector. Instead, the finding can be explained by Routine Activity Theory, because the first sector is composed of commercial banks with more assets and employees (Felson, 2010); if there are more 'suitable targets' (assets) and 'likely offenders' (employees), the organization is likely to suffer from more crime. Furthermore, a smaller number of controls ('capable guardian') in the community banking institutions might have led to a lower level of detection than in the first sector (Bussman and Werle, 2006; Johansson and Carey, 2016).

Moreover, the investment-culture relationship should be understood in a more nuanced way. In this study, we focused on 'organizational' investment and culture. The level of investment decided by management is the first step to set 'the strong tone at the top' in a company. Tversky and Kahneman's prospect theory (1992) implies that crime is a risk-seeking activity by facing the risk of punishment. Furthermore, individual perception of risk is affected by psychological framing (Fung, 2015; Huerta et al., 2012). If developing a strong culture by increasing anti-fraud investment can change employees' perceptions into a low crime and risk-averse pattern, this framing can spread out reinforcing virtuous cycles in a company, which will requires less investment in return (Kleiman, 2010). Therefore, our study gives an important message to CEOs or directors about the investment culture interaction to reduce employee's malpractice in organizations.

The present study also has several limitations. First, we directly asked the banking employees about 
the observed frequency of occupational fraud in the last five years. Of course, there might be gaps between actual and perceived fraud levels in companies. However, occupational fraud is regarded as so sensitive that it is very difficult to obtain real crime data in the banking industry (Button, 2008). Also, such information about illegal activities cannot be traced without potentially compromising the anonymity of the respondents. Instead, this study paid attention to the facts that occupational fraud could be detected most frequently by employees in a company (ACFE, 2012, 2014, 2016) and respondents are more likely to report that they observed others' unethical behaviour, rather than their own (Trevion et al., 1998).

Admittedly, the use of a micro-level endogenous variable (i.e., respondents' perceived level of fraud) raises concerns about the generalizability of our findings to macro-level set (i.e., fraud at the organisational level). Moreover, the mediating variable of ethical corporate culture (as a macro-level variable) was designed to predict the lower-level perception variable. Although this mismatched analytic framework is not confined to this study (Hechanova et al., 2014; Warren et al., 2014), it is still possible for our findings to be faced with a type I error. However, to use both bank type and organization size as controls in our analytical models would certainly ease the concerns pertaining to the mismatch issue to some extent. In other words, due to data limits, the current model specification was the least-worst option.

Despite the limitations above, our findings are significant because the study discovered an important pathway for fighting occupational fraud in organizations. Reducing employee fraud can be best achieved only through enhancing the ethical corporate culture, which indicates that the internalization of values mediates the relationship between the increased organizational investments and desired behavioral outcomes of the employees (Warren et al, 2014). According to Bandura's social learning theory (1977), increased anti-occupational fraud investment will raise the moral awareness of employees, which is a critical component of ethical decision making, and in sequence will decrease employees' fraud in organizations. Our findings also concur with the renowned corporate crime control strategy (i.e., family model regulation), that strongly enhanced organizational culture can buttress individuals' attitudes to not tolerate peer misconduct in the workplace (Braithwaite, 1989) or to use Fisse and Braithwaite's own words, "If we are serious about controlling corporate crime, the first priority should be to create a culture in which corporate crime is not tolerated" $(1983,246)$.

Furthermore, the current study has important policy implications, which is not confined to the Korean banking industry. Recently, Wells Fargo bank in the US, one of the biggest banks in the world, was fined by the US regulating authority because millions of fraudulent accounts were created without customer's agreement by some of their employees. The cause was not attributed to the lack of sufficient monitoring, but to inadequate organizational 'practice' and 'pressure' from the top, which measured success by the average number of products held by a customer (The New York Times, 2016). Therefore, this study can resonate not only through the Korean banking sector but also in other countries like the US. Without cultivating corporate culture, through investing in ethical leadership, values, and ethics programmes (Button and Brooks, 2009; Schwartz, 2013), monitoring controls will do nothing other than generate a "don't get caught" motivation for employees (Weaver and Trevino, 1999). Furthermore, our study also contributes to broadening the current fraud risk framework, the Fraud Triangle, by showing that ethical culture should be considered more importantly when assessing the fraud risk in organizations. 


\section{References}

Alleyne, B., Amaria, P., 2013. The effectiveness of corporate culture, auditor education, and legislation in identifying, preventing, and eliminating corporate fraud, International Journal of Business, Accounting, and Finance, 7(1). 34-62.

Apel, R., Nagin, D. S., 2011. General deterrence: A review of recent evidence. In Wilson, J. Q., Petersilia, J., Crime and Public Policy (411-436), Oxford University Press.

Albrecht, W. S., Albrecht, C. O., Albrecht, C. C., Zimbelman, M. F. 2015 (5 ${ }^{\text {th }}$ ed.), Fraud Examination, SouthWestern College.

American Institute of Certified Public Accountants (AICPA), 2016. Management override of internal control: The Achilles' heel of fraud prevention.

American Institute of Certified Public Accountant (AICPA), 2002. Statement on Auditing Standards, No. 99 : Consideration of Fraud in a Financial Statement Audit.

Association of Certified Fraud Examiners (ACFE), 2016. Report to the Nation on Occupational Fraud and Abuse, Austin Texas: ACFE.

Association of Certified Fraud Examiners (ACFE), 2015. Fraud Examiners Manual, Austin Texas: ACFE

Association of Certified Fraud Examiners (ACFE), 2014. Report to the Nation on Occupational Fraud and Abuse, Austin Texas: ACFE.

Association of Certified Fraud Examiners (ACFE), 2012. Report to the Nation on Occupational Fraud and Abuse, Austin Texas: ACFE.

Bandura, A. 1977. Social learning theory. Englewood Cliffs, NJ: Prentice Hall.

Batzeveg, E., Hwang, E., Han, S., 2017. Confidence in the police among Mongolian immigrants in South Korea and native Mongolians in Mongolia: A comparative test of conceptual models, International Journal of Law, Crime and Justice, 50, 61-70.

Bentley, K. A., Omer, T. C., Sharp, N. Y., 2013. Business strategy, financial reporting irregularities, and audit effort. Contemporary Accounting Research, 30(2), 780-817.

Black, W., 2013. The best way to rob a bank is to own one (Updated ed.). Austin: TX: University of Texas Press.

Bonny, P., Goode, S., Lacey, D., 2015. Revisiting employee fraud: gender, investigation outcomes and offender motivation. Journal of Financial Crime, 22(4), 447-467.

Braithwaite, J., 1989. Crime, shame and reintegration, Cambridge University Press.

Bussmann, K. D., Werle, M. M., 2006. Addressing Crime in Companies: First Findings from a Global Survey of Economic Crime, British Journal of Criminology, 46, 1128-1144.

Button, M. 2008. Doing security: critical reflections and an agenda for change, New York: Palgrave Macmillan.

Button, M., Brooks, G., 2009. "Mind the gap”, progress towards developing anti-fraud culture strategies in UK central government bodies. Journal of Financial Crime, 16(3), 229-244.

Button, M., Gee, J., 2013. Countering fraud for competitive advantage, Chichester, UK: John Wiley \& Sons.

Byrne, B. M., 2012. Structural equation modeling with Mplus: Basic concepts, applications and programming, New York, NY: Routledge.

Calavita, K., Pontell, H. N. 1991. Other's people's money revisited: collective embezzlement in the savings and loan and insurance industries, Social Problems, 38(1): 94-112.

Choi, J. H., Choi, S.,Hogan, C., Lee. J., 2013. The Effect of Human Resource Investment in Internal Control on the Disclosure of Internal Control Weaknesses. Auditing: A Journal of Practice \& Theory, 32(4), 169199.

Coleman, J. W., 1987. Toward an Integrated Theory of White-Collar Crime, The American Journal of Sociology, 93(2), 406-439.

Committee of Sponsoring Organizations of the Treadway Commission (COSO), 2013. Internal Control- 
Integrated Framework.

Cressey, D. R., 1953. Other People's Money: The Social Psychology of Embezzlement. New York, NY: The Free Press.

Datanet, Dec. 31. 2015. Deep learning and fraud detection technique (in Korean), Retrieved on Jan. 14. 2018 from http://www.datanet.co.kr/news/articleView.html?idxno=95643

Dorminey, J., Fleming, A. S., Kranacher, M. J., Riley, R. A., 2012. The Evolution of Fraud Theory, Issues in Accounting Education, 27(2), 555-579.

Dorminey, J., Fleming, A. S., Kranacher, M. J., Riley, R. A., 2010. Beyond fraud triangle: enhancing deterrence of economic crime, The CPA Journal (July), 16-23.

Edge, K. R., 2016. Preventing insider fraud and abuse, Tennessee Bar Journal, 12, 28 -30.

Enders, C. K., 2006. A primer on the use of modern missing-data methods in psychosomatic medicine research, Psychosomatic Medicine, 68, 427-436.

Erickson, M., Gibbs, J., Jensen, G. 1977. The deterrence doctrine and the perceived certainty of legal punishments. American Sociological Review, 42(Spring), 305-317.

Ethics Resource Center. 2010. The Importance of Ethical Culture: Increasing Trust and Driving Down Risks. Ethics Resource Center, Arlington, VA.

Felson, M., 2010. Crime and everyday life, Los Angeles: SAGE.

Fisse, B. and Braithwaite, J. (1983) The Impact of Publicity on Corporate Offenders, State University of New York Press.

Friedrich, D. O., 2010. Trusted Criminals: White Collar Crime in Contemporary Society, Cengage Learning.

Fung, M., 2015, Cumulative Prospect theory and managerial incentives for fraudulent financial reporting, Contemporary Accounting Research, 32(1), 55-75.

Giles, S. 2015. The Business Ethics Twin-Track: Combining Controls and Culture to Minimise Reputational Risk, Chichester: Wiley

Giles, S., 2012. Managing fraud risk: a practical guide for directors and managers, Chichester, West Sussex, UK: John Wiley and Sons.

Greenberg, J., 1990. Employee theft as a reaction to underpayment inequity: The hidden cost of pay cuts. Journal of Applied Psychology, 75(5), 561-568.

Greenlee, J., Fischer M., Gordon, T., Keating, E., 2007. An Investigation of Fraud in Nonprofit Organizations: Occurrences and Deterrents, Nonprofit and Voluntary Sector Quarterly, 36(4). 676-694.

Gunduz, M., Onder, O., 2013. Corruption and internal fraud in the Turkish construction industry, Science and Engineering ethics, 19, 505-528.

Hechanova, M., Melgar, I., Falguera, P., Villaverde, M., 2014. Organizational culture and workplace corruption in government hospitals, Journal of Pacific Rim Psychology, 8(2), 62-70.

Holtfreter, K., 2005a. Fraud in US Organisations: An Examination of Control Mechanisms. Journal of Financial Crime, 12(1), 88-95.

Holtfreter, K., 2005b. Is occupational fraud typical white-collar crime? A comparison of individual and organizational characteristics. Journal of Criminal Justice, 33, 353-365.

Holtfreter, K., 2008. Determinants of Fraud Losses in Nonprofit Organizations. Nonprofit Management \& Leadership, 19(1), 45-63.

Hollinger, R. C., Clark, J. P., 1983. Deterrence in the Workplace: Perceived Certainty, Perceived Severity and Employee Theft, Social Forces, 62(2), 398-418.

Hollow, M., 2014. Money, morals, and motives: An exploratory study into why bank managers and employees commit fraud at work, Journal of Financial Crime, 21(2), 174-190.

Huerta, E., Glandon, T., Petrides, Y., 2012. Framing, decision-aid systems, and culture: Exploring influences on fraud investigations. International Journal of Accounting Information Systems, 13(4), 316-333.

Johansson, E., Carey, P., 2016. Detecting fraud: The role of the anonymous reporting channel, Journal of Business Ethics. 139(2), 391-409.

Jang, H., Hwang, E., 2014. Confidence in the police among Korean people: An expressive model versus an 
instrumental model, International Journal of Law, Crime and Justice. 42(4), 306-323.

Kim, S, M., Sep. 9. 2015. National Assembly report on embezzlement statistics in the Korean banking sector (In Korean), Retrieved on Sep. 25. 2017 from https://m.blog.naver.com/v2030net/220475714549.

Kleiman, M., 2010. When brute force fails: How to have less crime and less punishment, Princeton: Princeton University Press.

Korean Broadcasting System News (KBS News), July, 6, 2012. Savings bank corruption. (In Korean) Retrieved on Sep. 25. 2017 from http://news.kbs.co.kr/news/view.do?ncd=2499202.

Kummer, T., Singh, K., Peter, B., 2015. The effectiveness of fraud detection instruments in not-for-profit organizations, Managerial Auditing Journal, 30(4/5), 435-455.

Lawrence, E., Kacmar, K., 2017. Exploring the Impact of Job Insecurity on Employees' Unethical Behavior. Business Ethics Quarterly, 27(1), 39-70.

Lokanan, M., 2015. Challenges to the fraud triangle: Questions on its usefulness, Accounting Forum, 39, 201224.

Lee, J., 2013, Essays on human resource investment in internal control, Graduate School of Business administration PhD thesis, Seoul National University.

Min, B. D., Oct. 24. 2012. National Assembly report on savings bank crisis (In Korean), Retrieved on Sep. 25. 2017 from http://bdmin.net/100170060595?Redirect=Log\&from=postView.

Mitchell, W. J., Lewis, P. V., Reinch Jr., N. L., 1992. Bank ethics: An exploratory study of ethical behaviors and perceptions in small and local bank, Journal of Business Ethics, 11, 197-205.

Muthen, L. K., Muthen, B.O., 1998-2012. Mplus User's Guide (7th ed.). Los Angeles, CA: Muthen \& Muthen.

Murphy, P. R., Free, C., 2016. Broadening the fraud triangle: Instrumental climate and fraud, Behavioral Research in Accounting, 28(1), 41-56.

Paternoster, R., 1989. Decisions to Participate in and Desist from Four Types of Common Delinquency: Deterrence and the Rational Choice Perspective. Law \& Society Review, 23(1), 7-40.

Paternoster, R., Simpson, S., 1996. Sanction threats and appeals to morality: testing a rational choice model of corporate crime, Law \& Society Review, 30(3), 549-583.

Preacher, K. J., Hayes, A. F., 2008. Asymptotic and resampling strategies for assessing and comparing indirect effects in multiple mediator models, Behavior Research Methods, 40, 879-891.

Rae, K., Subramaniam, N., 2008. Quality of internal control procedures: Antecedents and moderating effect on organisational justice and employee fraud, Managerial Auditing Journal, 23(2), pp.104-124.

Rossi, E. 2012. Five tips to reduce internal fraud, The CPA Journal, October, 14-15.

Rodgers, W., Soderbom A., Guiral, A. 2015., Corporate social responsibility enhanced control systems reducing the likelihood of fraud, Journal of Business Ethics, 131 (4). 871-882.

Saunders, A., Cornett, M., 2008. Financial Institutions Management: A Risk Management Approach ( $6^{\text {th }}$ ed.), New York: McGraw-Hill

Schafer, J. L., Graham, J. W., 2002. Missing data: Our view of the state of the art, Psychological Methods, 7, 147-177.

Schuchter, A., Levi, M., 2016. The fraud triangle revisited, Security Journal, 29(2), 107-121.

Schumacker, R. E., Lomax, R. G., 2010. A beginner's guide to structural equation modeling, New York, NY: Routledge, 2010.

Schwartz, M. S., 2013. Developing and sustaining an ethical corporate culture: the core elements, Business Horizon, 56(1), 39-50.

Simpson, S. S., Gibbs, C., Rorie, M., Slocum, L. L., Cohen, M. A., Vandenbergh, M., 2013. An empirical assessment of corporate environment crime-control strategies, The Journal of Law \& Criminology, 103(1), 231-278.

Singleton, T., Singleton, A., 2010. Fraud Auditing and Forensic Accounting (4th ed.). Hoboken, N.J.: John Wiley \& Sons Ltd.

Sutherland, E., 1961. White collar crime. New York; London: Holt, Rinehart and Winston.

The New York Times, Sep. 8. 2016, Wells Fargo Fined \$185 Million for Fraudulently Opening Accounts, 
Retrieved on Jan. 14. 2018 from https://www.nytimes.com/2016/09/09/business/dealbook/wellsfargo-fined-for-years-of-harm-to-customers.html.

The Kyunghyang Shinmun, Oct. 26. 2012. Savings bank crisis (In Korean), Retrieved on Sep. 25. 2017 from http://biz.khan.co.kr/khan_art_view.html?artid=201210262120315\&code=92030.

Timofeyev, Yuriy, 2015. Analysis of predictors of organizational losses due to occupational corruption, International Business Review, 24, 630-641.

Tipgos, M. A., 2002. Why management fraud is unstoppable, CPA Journal. 72(12), 34-41.

Trevino, L. K., Butterfield, K. D., McCabe, M. L., 1998, The ethical context in organizations: influences on employee attitudes and behaviours, Business Ethics Quarterly, 8(3), 447-476.

Tversky, A., Kahneman, D., 1992. Advances in prospect theory: Cumulative representation of uncertainty. Journal of Risk and Uncertainty, 5, 297-323.

Tunley, M., Button, M., Shepherd, D., Blackbourn, D., 2017. Preventing occupational corruption: utilizing situational crime prevention techniques and theory to enhance organizational resilience, Security Journal (In printing), 1-32.

Warren, D., Gasper, J., Laufer, W., 2014. Is formal ethics training merely cosmetic? A study of ethics training and ethical organizational culture, Business Ethics Quarterly, 24(1), 85-117.

Weisburd, D., Wheeler, S., Waring, E., Bode, N. 1991. Crimes of the middle class: White-collar offenders in the federal courts. New Haven, CT: Yale University Press

Wells, J., 1997. Occupational Fraud and Abuse. Texas: Obsidian Pub.

West, S. G., Finch, J., Curran, P., 1996. Structural equation models with nonnormal variables: Problems and remedies, In R. H. Hoyle (Ed.), Structural equation modeling: Concepts, issues, and application (5675). Thousand Oaks, CA: Sage.

Wheeler, S., Rothman, M., 1982. The Organization as Weapon in White Collar Crime. Michigan Law Review, $80,1403-1426$. 